\title{
CdS NANOPARTICLE-BASED BIOSENSOR DEVELOPMENT FOR AFLATOXIN DETERMINATION
}

\author{
Moh. Hayat ${ }^{1}$, Endang Saepudin $^{1}$, Yasuaki Einaga $^{2}$, Tribidasari A. Ivandini ${ }^{1^{*}}$ \\ ${ }^{1}$ Department of Chemistry, Faculty of Mathematics and Natural Science, Universitas Indonesia, \\ Kampus UI Depok, Depok 16424, Indonesia \\ ${ }^{2}$ Department of Chemistry, Faculty of Science and Technology, Keio University, \\ 3-14-1 Hiyoshi, Kohoku-ku, Yokohama 223-8522, Japan
}

(Received: September 2018 / Revised: April 2019 / Accepted: May 2019)

\begin{abstract}
An anodic stripping voltammetry detection method with lateral flow immunochromatographic assay for determining aflatoxin $\mathrm{M}_{1}$ was developed. Cadmium sulfide nanoparticles (CdSNPs) were employed as a label for aflatoxin antibody. Conjugation between the CdSNPs and aflatoxin antibody was performed as the first step. The CdSNP-antibody conjugate was then immobilized on a test strip on a conjugate pad. When the conjugate interacted with the sample containing aflatoxin, it was captured by the aflatoxin in the test zone. The CdSNPs retained in the test zone were then measured by anodic stripping voltammetry using a boron-doped diamond electrode. A linear concentration range of $0-70 \mathrm{ppb}$ aflatoxin, with a sensitivity of $20 \mu \mathrm{A} / \mathrm{mM}$ and a detection limit of $30 \mathrm{ppb}$, was achieved by this method.
\end{abstract}

Keywords: Aflatoxin; Anodic stripping voltammetry; Boron-doped diamond; CdS nanoparticles

\section{INTRODUCTION}

Aflatoxin is a secondary metabolite, mainly produced by Aspergillus flavus and Aspergillus parasiticus, which contaminate agricultural products, namely nuts, cereals and animal feeds (Bennett \& Klich, 2003). Six important types of aflatoxin have been identified and are denoted as $B_{1}, B_{2}, G_{1}, G_{2}, M_{1}$ and $M_{2}$ (Wacoo et al., 2014). Among these types, the International Agency for Research on Cancer classified aflatoxin $\mathrm{B}_{1}\left(\mathrm{AFB}_{1}\right)$ as a group 1 carcinogenic substance due to its ability to disrupt the induction of certain enzymes and inhibit RNA synthesis (IARC, 2002). Meanwhile, aflatoxin $\mathrm{M}_{1}\left(\mathrm{AFM}_{1}\right)$ is a hydrolyzed metabolite of $\mathrm{AFB}_{1}$, produced by the mammary gland; hence, it is mainly found in milk and dairy products, such as cheese and yoghurt (Martins $\&$ Martins, 2000). Due to its stability during pasteurization and other heat treatment (Wang et al., 2009), as well as its hepatotoxicity and carcinogenic effects (Badea et al., 2004), the aflatoxin content must be controlled. The regulated upper limits for $A F B_{1}$ and total aflatoxins $\left(B_{1}, B_{2}, G_{1}\right.$ and $\mathrm{G}_{2}$ ) are 30 and $50 \mu \mathrm{g} / \mathrm{kg}$ respectively, while that for $\mathrm{AFM}_{1}$ in milk is $1.0 \mu \mathrm{g} / \mathrm{kg}$. (IARC, 2002).

In recent years, many analytical techniques for quantitative aflatoxin determination have been studied, including thin layer chromatography (TLC), gas chromatography (GC) and highperformance liquid chromatography (HPLC) (Roseanu et al., 2010). These techniques are sufficiently sensitive for aflatoxin; however, GC and HPLC operation is time-consuming and

*Corresponding author's email: ivandini.tri@sci.ui.ac.id, Tel. +62-21-7270027, Fax. +62-21-7863432

Permalink/DOI: https://doi.org/10.14716/ijtech.v10i4.2407 
requires a skilled analyst, complex sample pre-treatment and expensive instrumentation, which affect aflatoxin detection in food products. Beside TLC, another fast detection method is immunochemistry. This can be used to detect aflatoxin in solid food (Betina, 1985; Shepard, 2009) as well as dairy products (Anfossi et al., 2008; Li et al., 2009). Immunochemistry has advantages with respect to its selectivity and sensitivity. One immunochemistry development is lateral flow immunoassay. Furthermore, enzyme-linked immunosorbent assay, which depends on a specific interaction between an antigen toxin target and its antibody, is also widely used to detect aflatoxin (Zhang et al., 2016). However, this method has several drawbacks, such as the requirement of an incubation period, together with time-consuming washing and mixing (Badea et al., 2004). Accordingly, the development of a new strategy for aflatoxin determination is urgently required.

To achieve a more suitable aflatoxin detection technique, several fast methods based on biosensors or immunosensor applications have recently been developed, including flow-injection immunoassay (Badea et al., 2004); a microcomb electrode modified with a self-assembly horseradish peroxidase (HRP) and anti-AFB 1 (Liu et al., 2006); and electrochemical methods (Piermarini et al., 2007; Parker \& Tothill, 2009; Linting et al., 2012; Chauhan et al., 2015; Zhang et al., 2016; Gouda et al., 2016; Kong et al., 2018; Peng et al., 2018). Additionally, Paniel et al. (2010) developed an electrochemical immunosensor for $\mathrm{AFM}_{1}$ in food products based on a competitive immunoassay with HRP as the label. A fast and simple immunochromatography test was also developed to detect $\mathrm{AFB}_{1}$ in less than 10 min. The developed $\mathrm{AFB}_{1}$ sensor test also shows no cross-reaction with ochratoxin A. (Moon et al., 2012).

Electrochemical measurements were have been performed by anodic stripping voltammetry (ASV) using a boron-doped diamond (BDD) as the working electrode. ASV is generally considered to be the most suitable method for trace metal detection, since this offers certain advantages for metal analysis, including excellent selectivity and sensitivity, a low detection limit, simple operation and a relatively low-cost process (Ivandini et al., 2012). BDD is superior to other conventional solid electrodes due to its wide potential window, low capacitance, chemical inertness, mechanical durability and exceptional biocompatibility (Fujishima et al., 2005, Ivandini \& Einaga, 2017). The use of the ASV technique for immunochromatographic test strips using BDD electrodes has been reported (Wicaksono et al., 2014; Ivandini et al., 2015; Hayat et al., 2016).

The above methods mainly yield only qualitative results. The electrochemical method offers accurate quantitative results but requires coupling with another relatively complex method. In this research, a method for determining aflatoxin was developed which combines the speed and reproducibility of the immunochromatography technique with the excellent selectivity and sensitivity of the electrochemical method. As a label, cadmium sulfide nanoparticles (CdSNPs) were used. These are suitable as labels in immunochromatographic sensors, since they are inexpensive and exhibit low potential oxidation, good electrical conductivity (Zheng et al., 2015), and high sensitivity (Du et al., 2012). Although no research has been conducted on the use of $\mathrm{CdS}$ as an aflatoxin label, CdSNPs have been investigated as labels for several biosensors, such as a cyanide ion sensor (Salariya et al., 2017), DNA (Svitkova et al., 2017), and glucose (Huang et al., 2005). Nanoparticles can be prepared by several methods, including the microwave technique (Usman et al., 2018), the hydrothermal method (Fadli et al., 2017), the alkaline hydrolysis method (Khalil et al., 2018), and microemulsions (Mirgorod \& Efimova, 2007). The advantages of the synthesis of nanoparticles in microemulsions are that the process occurs in mild conditions, and that the size and shape of the nanoparticles can be controlled by the micelle structure and dynamics (Mirgorod \& Efimova, 2007). 


\section{METHODOLOGY}

\subsection{Material}

Aflatoxin from A. flavus was supplied by Sigma Aldrich, USA. The aflatoxin antibody (anti$\mathrm{AFM}_{1}$ ) was made in our laboratory (Assaat et al., 2018) and purified as described by Prihantoro et al. (2017). Nitrocellulose membrane, Tween ${ }^{\circledR} 20$, sucrose, sodium azide, $\mathrm{Cd}\left(\mathrm{NO}_{3}\right)_{2}, \mathrm{Na}_{2} \mathrm{~S}$, sodium dioctyl sulphosuccinate (SDOSS) as surfactant, isooctane and other chemicals were obtained from Wako, Japan. All the chemicals were used without further purification. Pure water was obtained from a simple water system (Direct-Q UV 3-Millipore).

\subsection{Electrode Preparation}

The BDD electrode was prepared using microwave plasma-assisted chemical vapor deposition (MPACVD, ASTeX Corp., USA) with a mixture of $50 \mathrm{~mL}$ acetone and $4 \mathrm{~mL}$ trimethoxy borane as the precursor. The preparation was performed according to Fujishima et al. (2005). A particle size of $5 \mu \mathrm{m}$ was obtained with a film thickness of around $8 \mu \mathrm{m}$. The characterization by Raman spectroscopy (Renishaw System 2000, UK) generated a typical peak at $1333 \mathrm{~cm}^{-1}$ corresponding to the ansp ${ }^{3}$ carbon bond, and two peaks at 500 and $1200 \mathrm{~cm}^{-1}$ confirmed the presence of boron in the diamond structure (Ushizawa et al., 1998; Fujishima et al., 2005; Honda et al., 2013).

\subsection{CdS Nanoparticle and CdSNP-Anti Aflatoxin Conjugate Preparation}

The CdSNPs were prepared by the microemulsion method, in line with Mirgorod and Efimova (2007). Briefly, a mixture of water, $3.55 \mathrm{~g}$ sodium dioctyl sulphosuccinate and $60.5 \mathrm{~g}$ isooctane was divided into two parts $\left(31.7 \mathrm{~mL}\right.$ each). Then, $1 \mathrm{~mL}$ of $0.1 \mathrm{M} \mathrm{Cd}\left(\mathrm{NO}_{3}\right)_{2}$ solution was added to one part, while $1 \mathrm{~mL}$ of $0.1 \mathrm{M} \mathrm{Na}_{2} \mathrm{~S}$ was added to the other. The suspension was thoroughly stirred to completely disperse both solutions, followed by sonication for $5 \mathrm{~min}$. Subsequently, mixing and stirring were performed for several more seconds until a faint yellow colour appeared, indicating the formation of $\mathrm{CdS}$ particles. The solutions were evaporated to reduce their volume and a mixture of 3-mercaptopropionic acid $\left(20 \mathrm{mg} \mathrm{mL}^{-1}, 40.6 \mu \mathrm{L}\right)$ and sodium 3-mercapto-1propanesulphonate $\left(20 \mathrm{mg} \mathrm{mL}^{-1}, 68.16 \mu \mathrm{L}\right)$ was added. Precipitation was performed in a dark chamber at $23^{\circ} \mathrm{C}$ for $12 \mathrm{~h}$. The nanoparticles were subsequently washed with pyridine, hexane, ethyl acetate, ethanol and pure water to obtain a yellow CdS suspension. The washed precipitate was stored in $5 \mathrm{~mL} \mathrm{pH} 6$ phosphate buffer solution (PBS) for further use.

The CdSNP-anti-aflatoxin conjugate was prepared according to a procedure conducted by Valera et al., (2012). The obtained CdSNPs were added to $5 \mathrm{mM}$ PBS (437.5 $\mu \mathrm{L}, \mathrm{pH}$ 8.0). $125 \mu \mathrm{L}$ of this suspension was then added to $1.0 \mathrm{~mL} 5 \mathrm{mM}$ PBS containing $20 \mathrm{mM}$ 1-ethyl-3,3-dimethyl aminopropyl carbo diimide (EDC) solution and $10 \mathrm{mM}$ N-hydroxy succinimide (NHS), before stirring for $15 \mathrm{~min}$ at medium speed. The mixture was centrifuged, and the supernatant was isolated to remove excess reagent. The activated CdSNPs were then added to $2.0 \mathrm{~mL}$ aflatoxin antibody solution $\left(1 \mathrm{mg} \mathrm{mL}^{-1}\right.$ ), which had been previously dissolved in $0.5 \mathrm{~mL} 10 \mathrm{mM}$ PBS ( $\mathrm{pH}$ 7.4). The solution was then stirred for $12 \mathrm{~h}$ at $37^{\circ} \mathrm{C}$ to form a covalent bond between the activated CdSNP and aflatoxin antibody. The excess unreacted carboxyl group was blocked with glycine amino acid $\left(10 \mu \mathrm{L} 10 \mathrm{mg} \mathrm{mL}^{-1}\right)$ and re-stirred for $5 \mathrm{~h}$. The CdSNP-anti-aflatoxin conjugate was then suspended in $1 \mathrm{~mL}$ PBS (pH 8.0) to obtain $3.5 \mathrm{~mL}$ of $0.6 \mathrm{mg} / \mathrm{mL} \mathrm{CdSNP}$-anti-aflatoxin conjugate, which was stored at $4^{\circ} \mathrm{C}$ for further use.

\subsection{Test Strip Fabrication}

The test strips for the aflatoxin biosensors comprised a sample pad, a conjugate pad, a test line, a control line, an absorbent pad and a nitrocellulose membrane. All the components were arranged on a plastic sheet for support, as shown in Figure 1. 


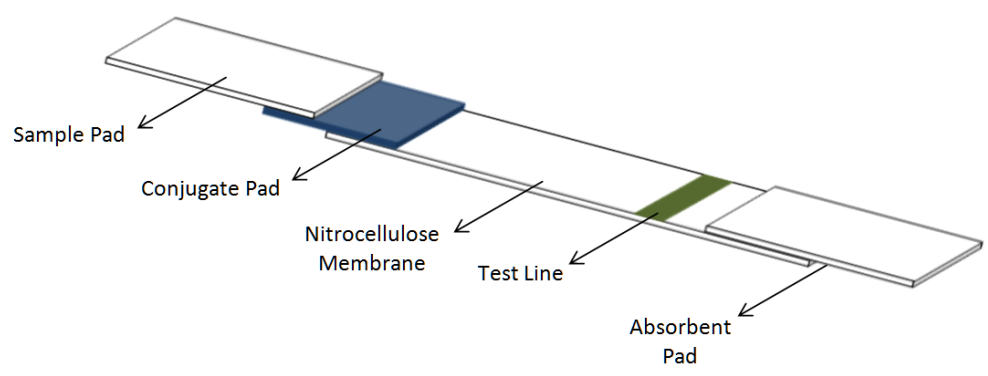

Figure 1 Scheme of immunochromatographic strip test assay

The sample pad was prepared by dropping the borate buffer solution containing bovine serum albumin (BSA) and Tween-20 onto a fibreglass pad, while the conjugate pad was prepared by dropping the same buffer solution containing BSA, Tween-20, sucrose and sodium azide onto conjugate pad. The pads were dried at $37^{\circ} \mathrm{C}$ over night. The nitrocellulose membrane was soaked in PBS and $150 \mu \mathrm{L} \mathrm{CdSNP-anti-aflatoxin} \mathrm{conjugate} \mathrm{was} \mathrm{then} \mathrm{dropped} \mathrm{onto} \mathrm{the} \mathrm{conjugate} \mathrm{pad}$ and redried.

\subsection{ASV Measurements}

ASV measurements were made in an electrochemical cell with a three-electrode system. BDD was used as the working electrode, while $\mathrm{Pt}$ wire and $\mathrm{Ag} / \mathrm{AgCl}$ were employed as the counter and reference electrodes respectively. A $0.1 \mathrm{M} \mathrm{HClO}_{4}$ solution was used as the electrolyte. Prior to the ASV measurement of the CdSNPs, the ASV measurement parameters, including the deposition potential, deposition time and scan rate were optimised for $\mathrm{Cd}^{2+}$ ions. ASV measurements of the test strips were then made based on the optimization results.

Aflatoxin detection using a CdS-based biosensor was achieved based on the competition between the aflatoxin immobilized on a test zone and the free aflatoxin contained in the tested sample. The measurement was made for a standard solution of aflatoxin $(0-70 \mathrm{ppb})$ prepared by dilution in methanol and a PBS mixed solution. During the measurements, the sample pad was soaked in each standard solution for $\sim 7 \mathrm{~min}$. Theoretically, the sample will move along the nitrocellulose membrane through the conjugate pad to the test line. Furthermore, the test zone was cut and dissolved in $4 \mathrm{~mL} 0.1 \mathrm{M} \mathrm{HClO}_{4}$ solution and left to react for $5 \mathrm{~min}$. Subsequently, electrochemical measurement was conducted by ASV.

\section{RESULTS AND DISCUSSION}

\subsection{CdS Nanoparticle and CdS-NP - Anti Aflatoxin Conjugate Preparation}

CdSNPs were prepared by the micro emulsion method, using $\mathrm{Cd}\left(\mathrm{NO}_{3}\right)_{2}$ as the $\mathrm{Cd}^{2+}$ source and $\mathrm{Na}_{2} \mathrm{~S}$ as the $\mathrm{S}^{2-}$ source, according to the following equation:

$$
\mathrm{Cd}\left(\mathrm{NO}_{3}\right)_{2(\mathrm{aq})}+\mathrm{Na}_{2} \mathrm{~S}_{(\mathrm{aq})} \rightarrow \mathrm{CdS}_{(\mathrm{s})}+2 \mathrm{Na}\left(\mathrm{NO}_{3}\right)_{(\mathrm{aq})}
$$

Since the reaction was performed in a dispersion system, the nanoparticle size could be obtained (Hayat et al., 2016). A dark yellow suspension indicated the formation of CdS particles. TEM images of the prepared CdSNPs (Figure 2) show that the nanoparticle size was around $7 \mathrm{~nm}$.

The CdSNP was then conjugated with aflatoxin antibody, based on the procedure introduced by Valera et al. (2012). EDC and NHS were employed to provide the active sites for the CdS, so that the aflatoxin antibody could be attached to the CdSNPs. BSA was then added to cover the excess active sites. 

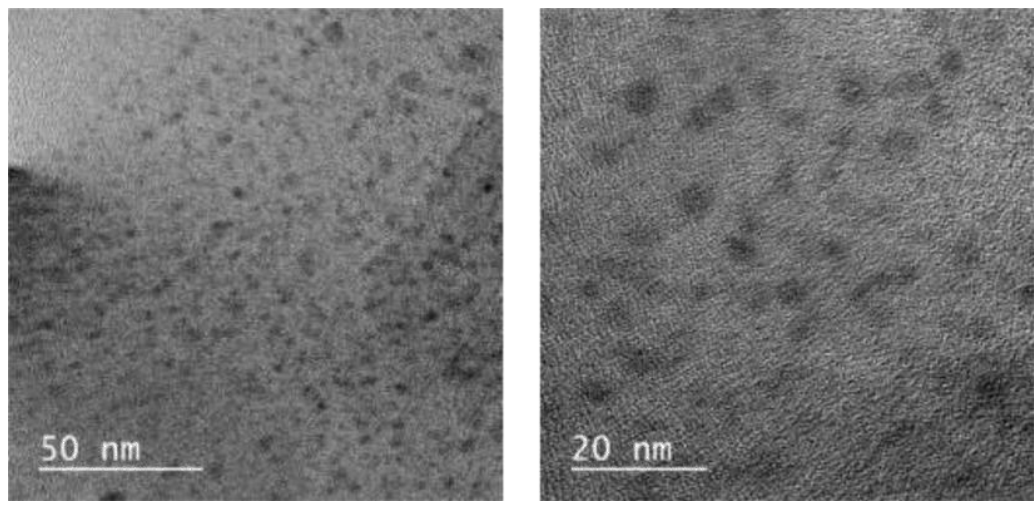

Figure 2 TEM images of the CdSNPs prepared by microemulsion

To characterize the conjugation between the CdSNPs and anti-aflatoxin, absorbance measurement was conducted by UV-Vis spectrophotometry in the wavelength range 350-600 nm (Figure 3). The CdSNPs show a sharp peak at around $470 \mathrm{~nm}$ due to the surface plasmon resonance of the nanoparticles. This peak shifted and broadened at around $500 \mathrm{~nm}$, indicating the presence of a new bond between the nanoparticle and antibody (Sharma et al., 2010).

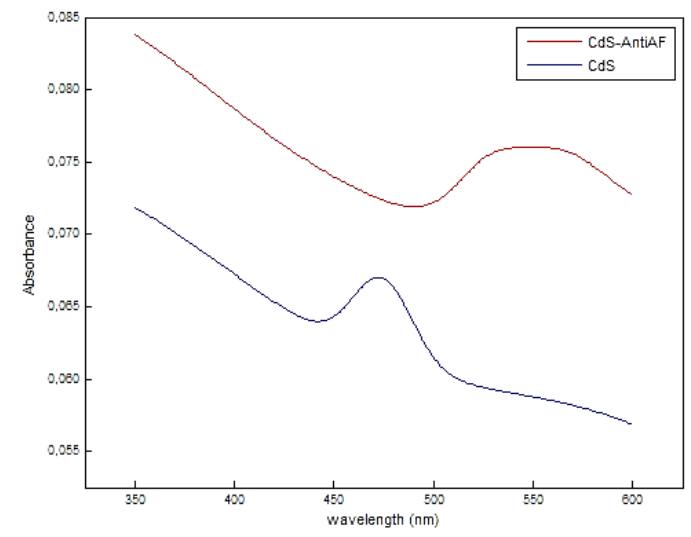

Figure 3 UV-Vis spectra of CdSNP and anti AFB-conjugated CdS NP

\subsection{ASV Optimization and Measurement}

ASV of $\mathrm{Cd}^{2+}$ ions in $0.1 \mathrm{M} \mathrm{HClO}_{4}$ was performed to optimize the measurement parameters. In our previous report, the oxidation peak of $\mathrm{Cd}^{2+}$ in $0.1 \mathrm{M} \mathrm{HClO}_{4}$ was obtained at $-0.6 \mathrm{~V}$ (vs. $\mathrm{Ag} / \mathrm{AgCl}$ ). A deposition potential of $-1.0 \mathrm{~V}$ ( $\mathrm{vs} \mathrm{Ag} / \mathrm{AgCl}$ ) with a deposition time of $60 \mathrm{~s}$ was applied, and the scan rate for the stripping step was $100 \mathrm{mV} / \mathrm{s}$ (Hayat et al., 2016). To optimize the parameters, in this work the deposition potential was varied in the range -1.0 to $-3.0 \mathrm{~V}$. Plots of the peak current against the $\mathrm{Cd}^{2+}$ concentration are summarized in Figure 4a.

It was clear that in the potential range between -1.0 and $-2.5 \mathrm{~V}$, the ASV slope increased with the deposition potential, while at a deposition potential of $-3.0 \mathrm{~V}$ it decreased compared to that at a potential of $-2.5 \mathrm{~V}$. Furthermore, at a potential of $-3.5 \mathrm{~V}$ and above, the response was undetected. Accordingly, a potential of $-2.5 \mathrm{~V}$ was selected for subsequent measurements.

The deposition time was varied using an applied potential of $-2.5 \mathrm{~V}$ in the time range of $60-600 \mathrm{~s}$. A summary of the peak currents versus the $\mathrm{Cd}^{2+}$ concentration is presented in Figure 4(b). The slope increased with the deposition time. However, at a deposition time of $360 \mathrm{~s}$, the peak current decreased at a high $\mathrm{Cd}^{2+}$ concentration. Moreover, the deposition time could not exceed $360 \mathrm{~s}$ due to the device limitations. Therefore, the time for subsequent measurements was fixed at 300 s. 


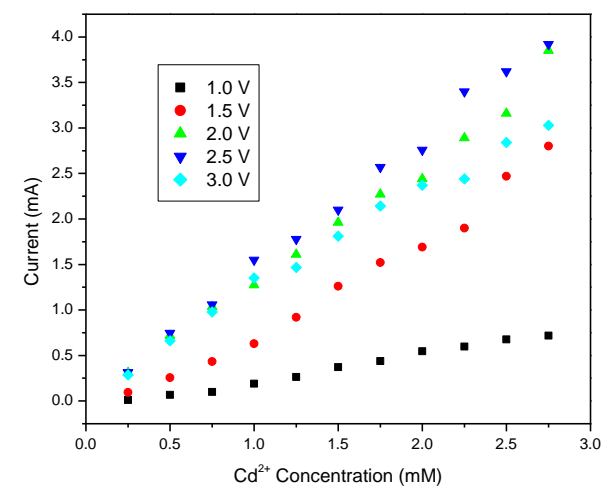

(a)

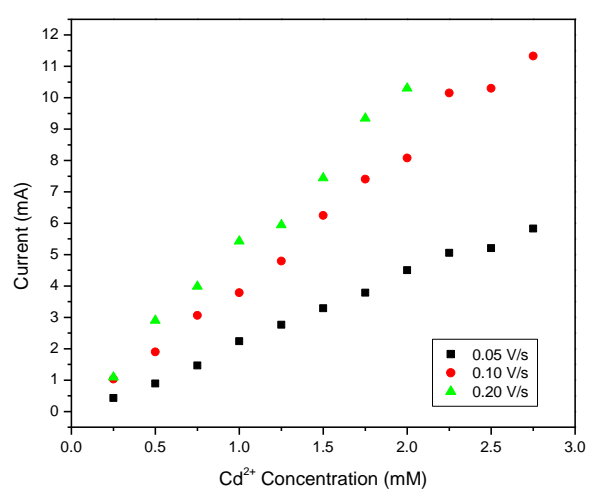

(c)

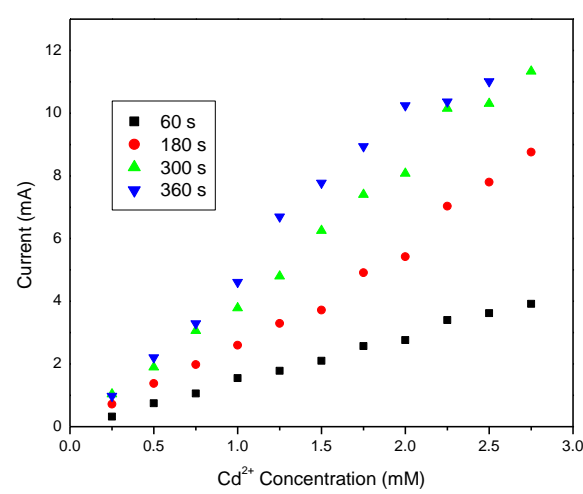

(b)

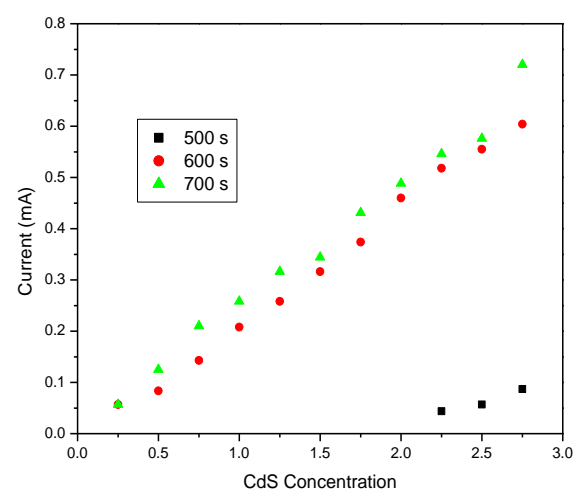

(d)

Figure 4 Anodic Stripping Voltammogram of $\mathrm{Cd}^{2+}$ in: (a) various deposition potentials; (b) deposition times; (c) scanrates; and (d) re-optimizing the measurement of CdS nanoparticles at deposition time variations of 500, 600, and $700 \mathrm{~s}$

The scan rate was optimized in the range of $0.05-0.20 \mathrm{~V} / \mathrm{s}$. A summary of the peak current vs. the $\mathrm{Cd}^{2+}$ concentration is presented in Figure 4c. This clearly shows that the ASV slope increased with the scan rate. At a scan rate of $0.2 \mathrm{~V} / \mathrm{s}$, an ASV response was detected with a $\mathrm{Cd}^{2+}$ ion concentration of up to $2.0 \mathrm{mM}$. However, at higher concentrations, no response was detected due to the device limitations. Based on these results, the scan rate for the following experiment was fixed at $0.1 \mathrm{~V} / \mathrm{s}$.

However, when ASV measurements of the CdSNPs were conducted in the concentration range of $0.625-3.750 \mathrm{mM}$ in $0.1 \mathrm{M} \mathrm{HClO}_{4}$ under optimum conditions (scan rate $0.10 \mathrm{~V} / \mathrm{s}$, deposition time $300 \mathrm{~s}$ and deposition potential $-2.5 \mathrm{~V}$ ), the ASV measurement produced no peak current for the CdSNPs. To resolve this problem, the deposition time was re-optimized by increasing it to 700s. The result is displayed in Figure 4d; based on this, the deposition time used for further experiments was 600s.

CdSNPs measured as $\mathrm{Cd}^{2+}$ ions were reflected by peak formation at $-0.6 \mathrm{~V}$, corresponding to the peak of $\mathrm{Cd}^{2+}$ shown in Figure 5a. This was consistent with our previous result (Hayat et al., 2016). In $\mathrm{HClO}_{4}$ solution, CdSNPs decomposed into $\mathrm{Cd}^{2+}$ and $\mathrm{S}^{2-}$ ions, according to the following reaction:

$$
\mathrm{CdS}+2 \mathrm{HClO}_{4} \rightarrow \mathrm{Cd}^{2+}+\mathrm{H}_{2} \mathrm{~S}+2 \mathrm{ClO}_{4}^{-}
$$




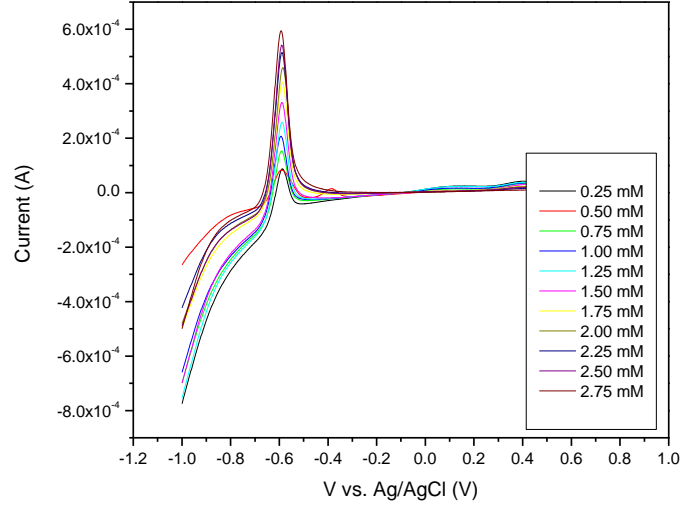

(a)

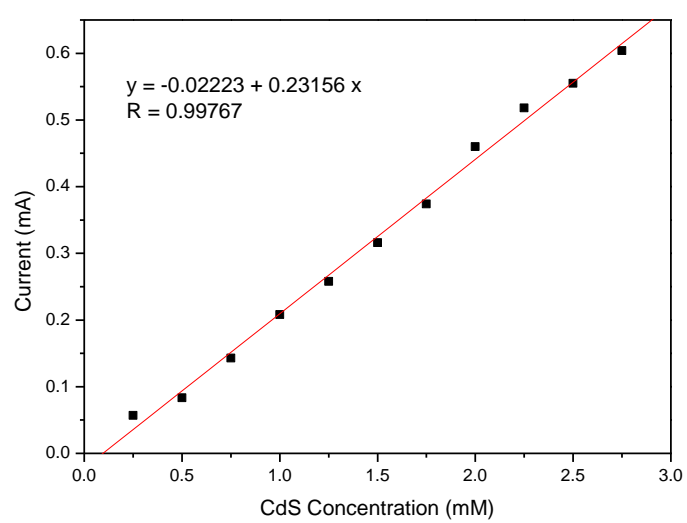

(b)

Figure 5 Anodic stripping voltammograms as responses of concentration variations of $\mathrm{CdS}(\mathrm{a})$ and the related calibration curve (b). Measurements were performed in $0.1 \mathrm{M} \mathrm{HClO}_{4}$ solution with a scan rate of $0.10 \mathrm{~V} / \mathrm{s}$, deposition time of $600 \mathrm{~s}$, and deposition potential of $-2.5 \mathrm{~V}$

Plots of the oxidation peaks at $-0.6 \mathrm{~V}$ against the $\mathrm{CdS}$ concentration are shown in Figure $5 \mathrm{~b}$; they show high linearity, indicating that $\mathrm{CdS}$ could be determined electrochemically using this method. In this case, CdSNPs can potentially be applied as labels in aflatoxin test strips. For this purpose, they were conjugated with anti-aflatoxin through an antigen-antibody reaction. CdSNPanti-aflatoxin will be bound by the aflatoxin in the sample. The application of CdS as a label on the test strip provided both qualitative and quantitative measurements. Qualitatively, this was determined by the formation of a yellow colour in the test zone, while quantitatively it was determined electrochemically. The CdS concentration measured by ASV reflects the aflatoxin concentration in the sample.

\subsection{Aflatoxin Test Strip Fabrication and Investigation}

The aflatoxin test strip was arranged on a nitrocellulose membrane equipped with a rigid thin plastic sheet on the back cover as a support and adhesive for the sample pad, release pad and absorbent pad. Each pad was arranged (sample pad, conjugate pad and absorbent pad) on the back cover. The conjugate pad used in this test strip was immobilized by the CdSNP-anti-aflatoxin conjugate, composed of three drops (each $50 \mu \mathrm{L}$ ). To ensure that the CdSNP-anti-aflatoxin conjugate was immobilized on the conjugate pad, each component was characterized using UVVis spectrophotometry at a wavelength of 350-600 nm, as shown in Figure 6. Comparing Figure 6 with Figure 3 confirms that the CdSNP-anti-aflatoxin conjugate was successfully immobilized on the conjugate pad.

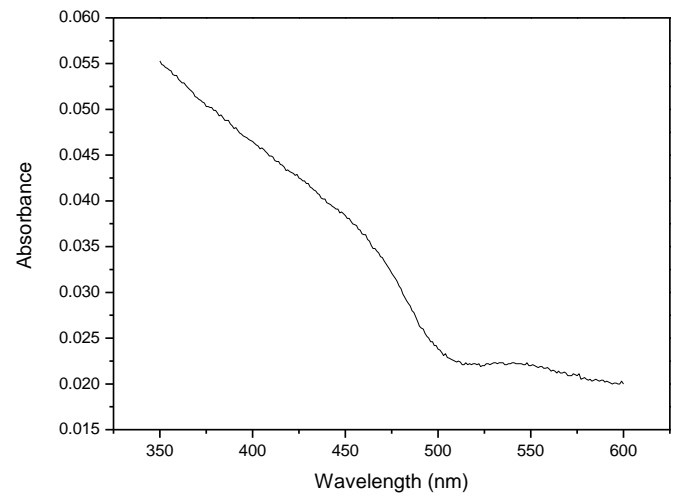

Figure 6 UV-visible spectrum of the conjugate CdS-NP - anti aflatoxin at a wavelength range of 350 to $600 \mathrm{~nm}$ 
Furthermore, the prepared test strip was examined to determine the aflatoxin standards from concentrations of 0 (blank) to $70 \mathrm{ppb}$ by ASV. A volume of $150 \mu \mathrm{L}$ CdSNP-anti-aflatoxin conjugate was immobilized on the conjugate pad. The test was conducted by dropping the aflatoxin standard onto the sample pad and leaving it for $10 \mathrm{~min}$ to ensure that the sample moved from the sample pad towards the test zone and absorbent pad. From visual observations, none of the samples changed color in the test zone. However, examination by ASV using the test strip parameters in Figure $7 \mathrm{a}$ showed a peak at around $-0.6 \mathrm{~V}$, which was similar to those in the voltammograms in Figure 5, indicating that $\mathrm{Cd}^{2+}$ in the form of a CdSNP-anti-aflatoxin conjugate in the test strips was measured.

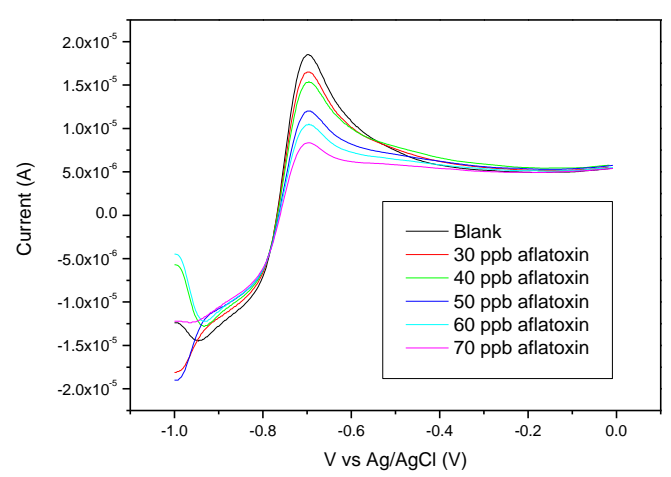

(a)

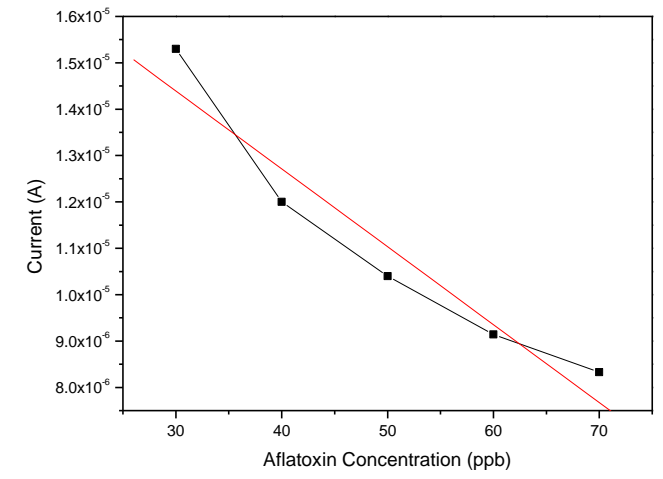

(b)

Figure 7 (a) Stripping voltammograms of the strip test prepared with $150 \mu \mathrm{L}$ of CdSNP-antiaflatoxin in the conjugate pad and $0.4 \mathrm{ppb}$ aflatoxin in the sample pad; and (b) the related linear curve of the aflatoxin standard sample in the concentration range of $0-70 \mathrm{ppb}$

Figure $7 \mathrm{a}$ also shows that the oxidation peak in the voltammograms decreased as the aflatoxin concentration increased. Plots of the peak currents against the aflatoxin concentration (Figure $7 \mathrm{~b}$ ) yield the linear equation $\mathrm{y}=1.94 \times 10^{-5}-1.68 \times 10^{-7} x\left(\mathrm{R}^{2}=-0.96\right)$ with a detection limit of 30 $\mathrm{ppb}$, indicating that the method is potentially suitable for determining aflatoxin in real-world applications.

\section{CONCLUSION}

ASV of $\mathrm{Cd}^{2+}$ in $0.1 \mathrm{M} \mathrm{HClO}_{4}$ showed positive results when applied to CdSNP-based aflatoxin biosensors. A deposition potential of $-2.5 \mathrm{~V}$ with a deposition time of $700 \mathrm{~s}$ and a scan rate of $100 \mathrm{mV} / \mathrm{s}$ generated an oxidation peak at $-0.6 \mathrm{~V}$. A linear correlation was observed between the decrease in the current peak and the increase in aflatoxin concentration in the range of 0-70 ppb, indicating that the method is promising for aflatoxin determination. The test strip was measured by anodic stripping voltammetry using a boron-doped diamond electrode. A linear concentration range of $0-70 \mathrm{ppb}$ aflatoxin, with a sensitivity of $20 \mu \mathrm{A} / \mathrm{mM}$ and a detection limit of $30 \mathrm{ppb}$, was achieved by this method.

\section{ACKNOWLEDGEMENT}

This work was funded by Hibah Tugas Akhir Mahasiswa Doktor Universitas Indonesia, under Contract No. 1334/UN2.R3.1/HKP05.00/2018.

\section{REFERENCES}

Anfossi, L., Calderara, M., Baggiani, C., Giovannoli, C., Arletti, E., Giraudi, G., 2008. Development and Application of Solvent-free Extraction for the Detection of Aflatoxin M1 
in Dairy Products by Enzyme Immunoassay. Journal of Agriculture and Food Chemistry, Volume 56(6), pp. 1852-1857

Assaat, L.D., Ivandini, T.A., Saepudin, E., 2018. Purification and Characterization of Polyclonal Antibody Against Acrylamide. In: AIP Conference Proceeding, Volume 2023(1)

Badea, M., Micheli, L., Messia, M.C., Candigliota, T., Marconi, E., Mottram, T., Velasco-Garcia, M., Mosconea, D., Palleschi, G., 2004. Aflatoxin M1 Determination in Raw Milk using a Flow-injection Immunoassay System. Analytica Chimica Acta, Volume 520(1-2), pp. 141148

Bennett, J.W., Klich, M., 2003. Mycotoxins. Clinical. Microbiology Reviews, Volume 16(3), pp. 497-516

Betina, V., 1985. Thin-layer Chromatography of Mycotoxins. Journal of Chromatography, Volume 334(3), pp. 211-276

Chauhan, R., Singh, J., Solanki, P.R., Basu, T., O’Kennedy, R., Malhotra, B.D., 2015. Electrochemical Piezoelectric Reusable Immunosensor for Aflatoxin B1 Detection. Biochemical Engineering Journal, Volume 103, pp. 103-113

Du, J., Yu, X., Di, J., 2012. Comparison of the Direct Electrochemistry of Glucose Oxidase Immobilized on the Surface of $\mathrm{Au}, \mathrm{CdS}$ and $\mathrm{ZnS}$ Nanostructures. Biosensors and Bioelectronics, Volume 37(1), pp. 88-93

Fadli, A., Amri A., Sari, E.O., Iwantono, Adnan A., 2017. Crystal Growth Kinetics of Magnetite $\left(\mathrm{Fe}_{3} \mathrm{O}_{4}\right)$ Nanoparticles using the Oswald Ripening Model. International Journal of Technology, Volume 8(8), pp. 1445-1454

Fujishima, A., Einaga, Y., Rao, T.N., Tryk, D.A. (Eds.), 2005. Diamond Electrochemistry, BKCElsevier, Tokyo, Japan

Gouda, K.Y., Catanantea, G., Hayata, A., Satyanarayana M, Gobib, K.V., Marty, J.L., 2016 Disposable and Portable Electrochemical Aptasensor for Label Freedetection of Aflatoxin B1 in Alcoholic Beverages. Sensors and Actuators B:Chemical, Volume 235, pp. 466-473

Hayat, M., Ivandini, T.A., Saepudin, E., Einaga, Y., 2016. Anodic Stripping Voltammetry of Synthesized CdS Nanoparticles at Boron-doped Diamond Electrodes. In: AIP Conference Proceedings, Volume 1729(1)

Honda, Y., Ivandini, T.A., Watanabe, T., Murata, K., Einaga, Y., 2013. An Electrolyte-free System for Ozone Generation using Heavily Boron-doped Diamond Electrodes. Diamond and Relate Material, Volume 40, pp. 7-11

Huang, Y., Zhang, W., Xiao, H., Li, G., 2005. An Electrochemical Investigation of Glucose Oxidase at a CdS Nanoparticles Modified Electrode. Biosensors Bioelectronics, Volume 21, pp. $817-821$

International Agency for Research on Cancer, 2002. IARC Monographs on the Evaluation of Carcinogenic Risks to Humans. IARC Lyon France, Volume 82, pp. 171-274

Ivandini, T.A., Wijaya, L., Gunlazuardi, J., Einaga, Y., 2012. Modification of Gold Nanoparticles at Carbon Electrodes and the Applications for Arsenic (III) Detections. Makara Journal of Science, Volume 16, pp. 9-14

Ivandini, T.A., Wicaksono, W.P., Saepudin, E., Rismetov, B., Einaga, Y., 2015. Anodic Stripping Voltammetry of Gold Nanoparticles at Boron-doped Diamond Electrodes and its Application in Immunochromatographic Strip Tests. Talanta, Volume 134, pp. 136-143

Ivandini, T.A., Einaga, Y. 2017. Heavy Metal Sensing based on Diamond Electrodes. CarbonBased Nanosensor Technology, Volume 17, pp. 1-20

Khalil, M., Liu, N., Lee, R.L., 2018. Super-Nernstian Potensiometric pH Sensor based on the Electrodeposition of Iridium Oxide Nanoparticles. International Journal of Technology, Volume (9)3, pp. 446-454 
Kong, Z., Wang, H., Zou, L., Ji, Z., 2018. Enhancement of Aflatoxin B1 Detection using Electrochemical Immunoassay Method and 2-aminoethanethiol. Material Research Express, Volume 5(6), pp. 2053-1591

Li, P., Zhang, Q., Zhang, W., 2009. Immunoassays for Aflatoxins. TrAC Trends Analytical Chemistry, Volume 28(9), pp. 1115-1126

Linting, Z., Ruiyi, L., Zaijun, L., Qianfang, X., Yinjun, F., Junkang, L., 2012. An Immunosensor for Ultrasensitive Detection of Aflatoxin B1 with an Enhanced Electrochemical Performance based on Graphene/Conducting Polymer/Gold Nanoparticles/the Ionic Liquid Composite Film on Modified Gold Electrode with Electrodeposition. Sensors and Actuators B: Chemical, Volume 174, pp. 359-365

Liu, Y, Qin, Z., Wu, X., Jiang, H., 2006. Immune-Biosensor for Aflatoxin B1 based Bioelectrocatalytic Reaction on Micro-comb Electrode. Biochemical Engineering Journal, Volume 32, pp. 211-217

Martins, M.L., Martins, H.M., 2000. Aflatoxin $\mathrm{M}_{1}$ in Raw and Ultra Hightemperature-treated Milk Commercialized in Portugal. Food Additives and Contaminants, Volume 17(10), 871874

Mirgorod, Y.A., Efimova, N. A., 2007. Relationship between Size of Cadmium Sulfide Nanoparticles and Water Pool Diameter in Reverse Micelles. Russian Journal of Applied Chemistry., Volume 80(9), pp. 1558-1561

Moon, J., Kim, G., Lee, S., 2012. A Gold Nanoparticle and Aflatoxin B1-BSA Conjugates Based Lateral Flow Assay Method for the Analysis of Aflatoxin B1. Materials, Volume 5(4), pp. 634-643

Paniel, N., Radoi A., Marty, J., 2010. Development of an Electrochemical Biosensor for the Detection of Aflatoxin M1 in Milk. Sensors, Volume 10(10), pp. 9439-9448

Parker, C.O., Tothill, I.E., 2009. Development of an Electrochemical Immunosensor for Aflatoxin M1 in Milk with Focus on Matrix Interference. Biosensensors and Bioelectronics, Volume 24(8), pp. 2452-2457

Peng, G., Li, X., Cui, F., Qiu, Q., Chen, X., Huang, H., 2018. Aflatoxin B1 Electrochemical Aptasensor based on Tetrahedral DNA Nanostructures Functionalized Three Dimensionally Ordered Macroporous MoS2-AuNPs Film. ACS Applied Materials and Interfaces, Volume 10(21), pp. 17551-17559

Piermarini, S., Micheli, L., Ammida, N.H.S., Palleschi, G., Moscone, D., 2007. Electrochemical Immunosensor Array using a 96-Well Screen-printed Microplate for Aflatoxin B1 Detection. Biosensors and Bioelectronics, Volume 22(7), pp. 1434-1440

Prihantoro, E.A.B., Saepudin, E., Ivandini, T.A., 2017. Purification of Aflatoxin B1 Antibody for the Development of Aflatoxin Biosensor. In: AIP Conference Proceedings, Volume 1862(1), 030076

Roseanu, A., Jecu, L., Badea, M., Evans, R.W., 2010. Mycotoxins: An Overview on Their Quantification Methods. Romanian Journal of Biochemistry, Volume 47(1), pp. 79-86

Salariya, K., Umar, A., Kansald, S.K., Mehta, S.K., 2017. Rapidly Synthesized Polyethylene Glycol Coated Cadmium Sulphide (CdS) Nanoparticles as Potential Scaffold for Highly Sensitive and Selective Lethal Cyanide Ion Sensor. Sensors and Actuators B: Chemical, Volume 241, pp. 276-284

Sharma, A., Matharu, Z., Sumarna, G., Solanki, P.R., Kim, C.G., Malhotra, B.D., 2010. Antibody Immobilized Cysteamine Functionalized-gold Nanoparticles for Aflatoxin Detection. Thin Solid Film, Volume 519(3), pp. 1213-1218

Shepard, G.S., 2009. Aflatoxin Analysis at the Beginning of the Twenty First Century. Analytical and Bioanalytical Chemistry, Volume 395(5), pp. 1215-1224

Svitkova, V., Blaskovicova, J., Tekelova, M., Kallaia, B.M., Ignata, T., Horackova, V., Skladal, P., Kopel, P., Adam, V., Farkasovae, D., Labuda, J., 2017. Assessment of CdS Quantum 
Dots Effect on UV Damage to DNA using a DNA/Quantum Dots Structured Electrochemical Biosensor and DNA Biosensing in Solution. Sensors and Actuators B: Chemical, Volume 243, pp. 435-444

Ushizawa, K., Watanabe, K., Ando, T., Sakaguchi, I., Nishitani-Gamo, M., Sato, Y., Kanda, H., 1998. Boron Concentration Dependence of Raman Spectra on $\{100\}$ and $\{111\}$ Facets of Bdoped CVD Diamond. Diamond and Related Materials, Volume 7(11-12), pp. 1719-1722

Usman, A., Kusrini, E., Widiantoro, A.B., Hardiya, E., Abdullah, N.A., Yulizar, Y., 2018. Fabrication of Chitosan Nanoparticles Containing Samarium Ion Potentially Applicable for Fluoresence Detection and Energy Transfer. International Journal of Technology, Volume 9(6), pp. 1112-1120

Valera, E., Muriano, A., Pividori, I., Sanchez-Baeza, F., Marco, M.P., 2012. Developement of a Coulombimetric Immunosensor based on Specific Antibodies with CdS Nanoparticles for Sulfonamide Antibiotic Residues Analysis and its Application to Honey Samples. Biosensors and Bioelectronics, Volume 43C(1), pp. 211-217

Wacoo, A.P., Wendiro, D., Vuzi P.C., Hawumba, J.F., 2014. Methods for Detection of Aflatoxin in Agricultural Food Crops. Journal of Applied Chemistry, Volume 2014(12), pp. 1-15

Wang, L., Dostálek, J., Knoll, W., 2009. Long Range Surface Plasmon-Enhanced Fluorescence Spectroscopy for the Detection of Aflatoxin M1 in Milk. Biosensors and Bioelectronics, Volume 24(7), 2264-2267

Wicaksono, W.P., Ivandini, T.A., Saepudin, E., Einaga, Y., 2014. Development of Immunochromatographic Strip Tests for Selective and Quantitative Detection of Melamine. Makara Journal of Science, Volume 18, pp. 96-100

Zhang, X., Chao-Rui L., Wei-Cheng W., Jian X., Ya-Ling H., Xian-Xian Y., Bin T., Xi-Peng Z., Chuang S., Shi-Jia D., Jing-Fu Q., 2016. A Novel Electrochemical Immunosensor for Highly Sensitive Detection of Aflatoxin B1 in Corn using Single-Walled Carbon Nanotubes/Chitosan. Food Chemistry, Volume 192, pp. 197-202

Zheng, D., Zhang, G., Wang, X., 2015. Integrating CdS Quantum Dots on Hollow Graphitic Carbon Nitride Nanospheres for Hydrogen Evolution Photocatalysis. Applied Catalysis B: Environmental, Volume 179, pp. 479-488 